\title{
Fatores de risco e possíveis causas de Esquistossomose na população residente das margens do riacho de canas em Itapicuru - BA
}

\author{
Risk factors and possible causes of schistosomiasis in the residente population of the \\ banks of the sugarcane stream in Itapicuru - BA \\ Factores de riesgo y posibles causas de esquistosomiasis em la población residente de \\ las márgenes del riacho de cañas em Itapicuru - BA \\ Wellington Pereira Rodrigues ${ }^{1 *}$, Priscila Dantas Gonçalves ${ }^{1}$, Patrícia Silva do Nascimento Santiago .
}

\begin{abstract}
RESUMO
Objetivo: O presente estudo, tem como objetivo realizar um levantamento sobre os fatores de risco e possíveis causas da esquistossomose na população Ribeirinha, residentes às margens do Riacho da Fazenda Canas no município de Itapicurú-Bahia. Método: Neste contexto, a pesquisa empregada no presente estudo é uma pesquisa de campo, possuindo caráter quantitativo, pois busca-se descobrir quantos entrevistados já forma infectados pelo $S$. mansoni, assim foi necessário realizar uma pesquisa de caráter exploratório e explicativo. Resultados: Como se nota, $18 \%$ da população pertencem ao sexo masculino, o que representa a $36,0 \%$ da população, enquanto $32 \%$ são do sexo feminino, equivalente a $64,0 \%$ dos entrevistados. Das $24,0 \%$, doze pessoas têm até 20 anos; $8,0 \%$ quatro pessoas estão na faixa etária de 20 (vinte) a 30 (trinta) anos, e $60,0 \%$ trinta e quatro pessoas têm de 30 ou mais anos de idade, sendo constatado que a população pesquisada é composta pela maioria absoluta de adultos. Ao ser questionado se o entrevistado ou sua família toma banho, já tomou, ou lava roupas no riacho, 98,0\% responderam "SIM", enquanto 2,0\%, apenas uma pessoa, respondeu "NÃO". Conclusão: Todas estas descobertas mostram a necessidade de uma educação em saúde voltada para a prevenção da esquistossomose, tendo em vista o número de casos de na população Ribeirinha residentes às margens do Riacho de Canas, em se tratando da gravidade da doença.
\end{abstract}

Palavras-chave: Esquistossomose, Schistossoma Mansoni, Morbidade.

\section{ABSTRACT}

Objective: The objective of this study is to conduct a survey about the risk factors and possible causes of schistosomiasis in the Ribeirinha population, living on the banks of Fazenda Canas Creek in the city of Itapicurú-Bahia. Method: In this context, the research employed in the present study is a field research, having a quantitative character, because it is sought to find out how many interviewees already infected with $\mathrm{S}$. mansoni, so it was necessary to perform an exploratory and explanatory research. Results: As can be seen, $18 \%$ of the population belong to the male sex, representing $36.0 \%$ of the population, while $32 \%$ are female, equivalent to $64.0 \%$ of the respondents. Of the $24.0 \%$, twelve people are under $20 ; 8,0 \%$ four people are in the age group of 20 (twenty) to 30 (thirty) years, and $60,0 \%$ are thirty and four people of 30 or more years of age, being verified that the population researched is composed by the majority absolute of adults. When asked whether the respondent or his family had a bath, had already taken or washed clothes in the creek, $98.0 \%$ answered "YES", while 2.0\%, only one person answered "NO". Conclusion: All these findings show the need for a health education focused on the prevention of schistosomiasis, considering the number of cases in the Ribeirinha population living on the banks of the Canas Creek, considering the severity of the disease.

Key words: Schistosomiasis, Schistosoma Mansoni, Morbidity.

${ }^{1}$ Centro Universitário AGES (UniAGES), Paripiranga - BA. * E-mail: wellington life@live.com SUBMETIDO EM: 1/2019 | ACEITO EM: 2/2019 | PUBLICADO EM: 4/2019 


\section{RESUMEN}

Objetivo: El presente estudio, tiene como objetivo realizar un levantamiento sobre los factores de riesgo y posibles causas de la esquistosomiasis en la población Ribeirinha, residentes a orillas del Riacho da Fazenda Canas en el municipio de Itapicurú-Bahía. Método: En este contexto, la investigación empleada en el presente estudio es una investigación de campo, teniendo carácter cuantitativo, pues se busca descubrir cuantos intrevistados ya forma infectados por el $S$. mansoni, así fue necesario realizar una investigación de carácter exploratorio y explicativo. Resultados: Como se nota, el $18 \%$ de la población pertenece al sexo masculino, lo que representa el $36,0 \%$ de la población, mientras que el $32 \%$ es del sexo femenino, equivalente al $64,0 \%$ de los entrevistados. De las 24,0\%, doce personas tienen hasta 20 años; El 8,0\% cuatro personas están en el grupo de edad de 20 a 30 años, y el 60,0\% treinta y cuatro personas tienen de 30 o más años de edad, siendo constatado que la población encuestada está compuesta por la mayoría absoluta de adultos. Al ser preguntado si el entrevistado o su familia se baña, ya tomó, o lava ropas en el arroyo, el 98,0\% respondió "SI", mientras que el 2,0\%, sólo una persona, respondió "NO". Conclusión: Todos estos descubrimientos muestran la necesidad de una educación en salud orientada a la prevención de la esquistosomiasis, teniendo en cuenta el número de casos en la población ribereña residentes a orillas del Riacho de Canas, en lo que se refiere a la gravedad de la enfermedad.

Palabras clave: La esquistosomiasis, el Schistossoma Mansoni, la morbilidad.

\section{INTRODUÇÃO}

O esquistossomo é um parasita platelminto da classe trematóide que reside em áreas infectadas compostas pela precariedade do saneamento, fazendo assim relações com as populações mais carentes a nível socioeconômico. O Schistosoma tem como hospedeiros intermediários no Brasil as classes de caramujos, como B. glabrata, $B$. tenagophila e B. straminea. Logo, sua transmissão decorre do aparecimento de pessoas contaminadas, em que este pode excretar o ovo contendo o helminto através fazes, transmitindo assim sua infecção. A doença possui uma extrínseca relação com a classe social, além disso, a ausência de tratamento de esgoto e de água, saneamento básico, acesso aos serviços de saúde e as baixas condições socioeconômicas são fatores determinantes para a endemia esquistossômica das regiões estudadas (JACOBI PR, 2013).

A esquistossomose é causada pelo parasita Schistosoma Mansoni, que penetra no organismo humano liberando ovos, sendo eliminados pelas fezes. Esses ovos em contato com a água eclodem, dando origem a um miracídio que é considerado a fase inicial dos vermes trematódeos, logo segue-se em seu primeiro estágio de ciclo vital. Em seguida, esses miracídios procuram e penetram no seu hospedeiro intermediário que é o molusco se desenvolvendo e saindo para o meio externo em forma de cercária. Estas cercárias são as formas multicelulares desenvolvidas dos miracídios, em que abandonam o molusco e nadam até a água, assim procuram um hospedeiro definitivo como o homem, para penetrar na sua pele e invadir o organismo provocando a esquistossomose (BARACHO M, 2013).

Para que ocorra a transmissão da esquistossomose é preciso que haja ambiente propício e indivíduos suscetíveis. Assim, alguns fatores são contribuintes para a incidência e prevalência da esquistossomose, dentre eles a falta de saneamento básico, coleções hídricas contaminadas, moluscos do gênero Biomphalaria, condições ambientais favoráveis como altas temperaturas e boa luminosidade, e falta de educação sanitária (BARBOSA CS, 2013).

A esquistossomose é considerada um grave problema de saúde pública, pelo seu poder de expansão bem como o alto grau de morbidade, provocando a morte de milhares de pessoas no mundo (BRASIL, 2014). No Brasil, estima-se cerca de 1,5 milhões de pessoas vivem em áreas com risco de contrair a esquistossomose, o que coloca a país entre os 78 países em que a doença permanece endêmica, assim mais de $60 \%$ da população encontra-se sem acesso a esgotamento sanitário. Os estados das regiões do nordeste e sudeste 
são mais afetados, logo tendo concordância que essa ocorrência está diretamente interligada à presença de moluscos responsáveis pelas transmissões (IBGE, 2015).

No Nordeste, o estado de Sergipe aponta resultados apontaram uma média de 17,3\% de predomínio da doença no período de 1980 a 1989, segunda maior de Brasil, menor apenas a do que estado de Alagoas. Ela pode se manifestar em duas fases: fase aguda e fase crônica (COLLEY DG, 2014). Na fase aguda alguns indivíduos se mantêm assintomáticos. Já na fase crônica, o sujeito apresenta sintomatologia diversa podendo ocorrer ascite, varizes no esôfago, hepatoesplenomegalia e até problemas nos rins e Sistema Nervoso Central (SNC) (BRASIL, 2014).

O diagnóstico da esquistossomose é feito de forma simples, através do exame parasitológico de fezes, no qual é contabilizado a quantidade de ovos, sendo que se resultado positivo é iniciado o tratamento através de medicamentos por via oral. Os medicamentos utilizados são o praziquantel e oxamniquina (INOBAYA MT, 2014). É preciso realizar a educação em saúde, com o intuito de explicar a população sobre a doença, as formas de transmissão e prevenção, bem como adotar medidas para eliminação do hospedeiro intermediário, o caramujo impedindo a continuidade do seu ciclo biológico (GUERRA AJT, 2012).

Assim, este estudo tem como principal objetivo, realizar levantamento dos fatores de ricos e possíveis causas de esquistossomose na população ribeirinha residentes às margens do Riacho de Canas no município de Itapicurú-Ba, buscando identificar possíveis fontes de contaminação S. Mansoni. Além disto, objetiva-se especificamente avaliar o saneamento básico dos moradores da Fazenda Canas, como um condicionante, na infecção do parasita Shistosoma mansoni identificando as possíveis fontes de contaminação, e infestação do molusco do gênero Biomphalaria. Compreender as possíveis causas que propiciam a continuação do ciclo biológico do parasita Shistosoma mansoni.

\section{MÉTODOS}

Para realizar o levantamento sobre a incidência de esquistossomose na população ribeirinha, residentes no Povoado de Canas, localizada no município de Itapicuru/BA, foi necessário realizar uma pesquisa de caráter exploratório e explicativo. Uma pesquisa exploratória consiste num instrumento de coleta de dados, que serve como subsídio para identificar os fatores determinantes e condicionantes no desenvolvimento da patologia. Já a pesquisa explicativa, busca explicar as possíveis causas que levam ao surgimento da doença (GIL AC, 2010).

Neste contexto, a pesquisa empregada no presente estudo é uma pesquisa de campo, possuindo caráter quantitativo, pois busca-se descobrir quantos ribeirinhos residentes às margens do Riacho de Canas, já forma infectados pelo $S$. mansoni. De acordo com o Agente comunitário de saúde (ACS), a população que reside às margens do Riacho de Canas, na fazenda Canas no Município de Itapicurú Bahia, possui 134 habitantes. Dentre estes foram entrevistados 50 moradores da comunidade. Foi empregada uma pesquisa com a amostragem probabilista aleatória simples sem reposição. Este tipo de abordagem se dá basicamente por uma amostragem ao acaso, onde serão entrevistados apenas parte da população, e cada indivíduo só poderá participar da amostra apenas uma vez. (GIL, 2010).

Para realizar o diagnóstico situacional referente ao saneamento básico e ao número de pessoas infectadas pelo parasita Schistosoma Mansoni foi utilizado como estratégia um questionário. O questionário empregado, compreende num questionário estruturado, apresentando 22 questões, pré-estabelecido de forma padronizada, contendo questões abertas e fechadas, com ênfase no colhimento de informações relacionadas ao saneamento básico e ao conhecimento da população sobre a esquistossomose e seus fatores causais, bem como quantificar indivíduos que já foram infectados pelo S. Mansoni.

Para realização da coleta de dados, a aplicação do questionário, e os dados obtidos pela Secretaria de Saúde, fez-se necessário apresentar o Termo de Consentimento Livre e Esclarecido, aprovado pelo presidente do Conselho de Ética da Faculdade Ages no 086-2014, obedecendo às normas institucionais da Faculdade Ages. 


\section{RESULTADOS E DISCUSSÃO}

Após os dados coletados através da aplicação do questionário, segue a análise dos gráficos e tabelas referentes aos resultados da pesquisa. É de extrema importância a discussão da pesquisa, pois é mediante ao diagnóstico que se chegará uma conclusão fidedigna do que fora investigado. Na visão de Suzanne (2015), uma pesquisa é considerada uma viagem, que gera reflexão e descobertas, sendo que o investigador observa por uma ótica crítica e analítica, compreendendo o problema em estudo.

Tabela 1 - Respostas dos entrevistados relacionados aos dados sociodemográficos, 2018.

\begin{tabular}{|c|c|c|}
\hline \multicolumn{3}{|c|}{ Tempo que residem na comunidade } \\
\hline Mais de três anos & 3 & 6,0 \\
\hline Mais de cinco anos & 1 & 2,0 \\
\hline Mais de dez anos & 46 & 92,0 \\
\hline TOTAL & 50 & 100,0 \\
\hline Situação de Moradia & Frequência (50) & Percentual (\%) \\
\hline Casa própria & 50 & 100 \\
\hline Casa alugada & 0 & 0,00 \\
\hline Número de cômodos & Quantidade & $\%$ \\
\hline Três & 2 & 4,00 \\
\hline Quatro & 3 & 6,00 \\
\hline Cinco & 4 & 8,00 \\
\hline Seis & 10 & 20,00 \\
\hline Sete & 12 & 24,00 \\
\hline Oito & 13 & 26,00 \\
\hline Nove & 4 & 8,00 \\
\hline Dez & 2 & 4,00 \\
\hline TOTAL & 50 & 100,0 \\
\hline Número de moradores na mesma casa & Frequência (50) & Percentual (\%) \\
\hline 1 (uma) & 3 & 6,00 \\
\hline 2 (duas) & 6 & 12,00 \\
\hline 3 (três) & 11 & 22,00 \\
\hline 4 (quatro) & 14 & 28,00 \\
\hline 5 (cinco) & 9 & 18,00 \\
\hline 11 (onze) & 7 & 14,00 \\
\hline Energia elétrica & Frequência (50) & Percentual (\%) \\
\hline Sim & 49 & 98,00 \\
\hline Não & 1 & 2,00 \\
\hline Rede de esgoto & Frequência (50) & Percentual (\%) \\
\hline Sim & 0 & 0,00 \\
\hline Não & 50 & 100 \\
\hline Uso do banheiro & Frequência (50) & Percentual (\%) \\
\hline Sim & 43 & 86,00 \\
\hline Não & 7 & 14,00 \\
\hline Água encanada & Frequência (50) & Percentual (\%) \\
\hline Sim & 49 & 98,00 \\
\hline Não & 1 & 2,00 \\
\hline
\end{tabular}

Fonte: Dados coletados pelo pesquisador, 2018.

A identificação do sexo é, sem dúvida, um fator considerável na pesquisa, pois ajuda a conhecer sobre a população estudada. Porém, de acordo com Jordão MCC (2014) a infecção pelo parasita Schistosoma Mansoni acomete qualquer indivíduo independente de sexo ou idade, desde que estes frequentem ambientes 
propícios a infecção, como coleções hídricas contaminadas. Logo, Brasil (2014) afirma que cada indivíduo possui especificações singulares, mas em qualquer faixa etária, ele pode adquirir a esquistossomose, se este vir a ter contato com a cercária, presentes em coleções hídricas contaminadas pelo Schistossoma Mansoni.

Na opinião de Silva PCV e Domingues ALC (2011) a renda familiar possui forte influência na infecção pelo parasita Schistosoma Mansoni, pois determina a pobreza, sendo que esta, está associada a péssimas condições de higiene, e ausência de saneamento básico, o que faz com que as pessoas utilizem águas contaminadas para consumo doméstico, banho e lazer.

A pesquisa também procurou evidenciar o total de pessoas que residem em cada moradia. Como se observa na tabela 1 , das cinquenta pessoas estudadas, $(14 ; 28,0 \%)$ afirmaram que residem quatro pessoas em cada moradia. Em segundo lugar, encontra-se o percentual de $(11 ; 22,0 \%)$ que responderam que em suas moradias habitam três pessoas, já $(9 ; 18,0 \%)$ disseram que cinco pessoas residem em cada moradia, ( 7 ; $14,0 \%)$ confirmaram que suas moradias são habitadas por onze pessoas, cada, logo $(6 ; 12,0 \%)$ afirmam que, em cada casa, moram duas pessoas, e finalmente ( $3 ; 6,0 \%)$ informaram que moram sozinhos em suas casas. Em conformidade ao supracitado, para que haja a redução da esquistossomose faz-se necessário além de promover saúde, reabilitar a comunidade quanto aos riscos ocasionados pelo parasita esquistossômico. Assim, as formas de tratamento poderão reduzir os índices de disseminação da doença. (ABDEL-HAFEEZ EH et al., 2015).

Como demonstra a tabela 1, a maioria das famílias (28\%) que moram na Fazenda Canas no município de Itapicurú Bahia, é composta por quatro pessoas. No entanto observa-se, em número menor (14\%) das famílias com até onze moradores. Em adição, verifica-se que, há uma desigualdade no que se refere as condições socioeconômicas da população ribeirinha residentes na fazenda Canas, o que para Espirito-Santo MCC et al. (2015), a condição socioeconômica de uma população pode ser considerada uma injustiça social, pois há uma estreita relação entre elas, interferindo nas condições de saúde do indivíduo.

De acordo com o supracitado e com relevância ao ministério da saúde, a classificação da esquistossomose e sua devida prevalência pode ser considerada pelas áreas de baixas endemicidade, prevalecendo porcentagens abaixo de 5\%, média endemicidade entre $5 \%$ e a $15 \%$ e alta prevalência, sendo este maior a $15 \%$ (SAUCHA CVV et al., 2015).

Tabela 2 - Hábitos que expõe a população a risco de contrair a doença, 2018.

\begin{tabular}{lcc}
\hline \multicolumn{1}{c}{ Formas de lazer } & Frequência & Percentual(\%) \\
\hline Visitar amigos e familiares & 3 & 6,00 \\
Leitura, dança e passeio & 6 & 12,00 \\
Trabalhar e jogar bola (futebol) & 11 & 22,00 \\
Assistir televisão e ir à feira livre & 16 & 32,00 \\
Ir à igreja & 9 & 18,00 \\
Ir à escola, cantar ou brincar & 5 & 10,00 \\
TOTAL & $\mathbf{5 0}$ & $\mathbf{1 0 0}$ \\
\hline
\end{tabular}

Fonte: Dados coletados pelo entrevistador, 2018.

Todo ser humano procura realizar alguma determinada atividade para aliviar o estresse do cotidiano, ou simplesmente para se sentir bem. Não tão diferente, a população pesquisada também procura realizar atividades que possibilitam lazer aos mesmos.

Na tabela 2 se nota que $(16 ; 50 \%)$ dos entrevistados apontam assistir televisão e ir à feira livre como a principal forma de lazer, equivalente a $32,00 \%$ da população; $(11 ; 22,0 \%)$ decidem trabalhar e jogar futebol; (6; $12,0 \%)$ optam pela leitura, dança e passeio; $(3 ; 6,0 \%)$ preferem visitar amigos e familiares; $(9 ; 18,0 \%)$ escolhem ir à igreja; $(5 ; 10,0 \%)$ escolhem ir à escola, cantar ou brincar como forma de laser. 
Tabela 3 - Respostas dos entrevistados quando questionados sobre "o que você sabe sobre saneamento.

\begin{tabular}{lcc}
\hline Respostas & Frequência & Percentual (\%) \\
\hline Para preservar a saúde e a população & 2 & 4,0 \\
Queimar lixo & 2 & 4,0 \\
Rede de esgoto & 1 & 2,0 \\
Tratamento de esgoto & 1 & 2,0 \\
Queimar lixo e ter rede de esgoto & 1 & 2,0 \\
Fossa, rede de esgoto & 1 & 2,0 \\
Sei (não entanto, não disse o que era) & 1 & 2,0 \\
Não pode comer sem lavar as mãos & 1 & 2,0 \\
Não fazer as necessidades a céu aberto (defecar) & 1 & 2,0 \\
Uma forma de higienização & 2 & 4,0 \\
Uma forma de higienização e cuidado com a saúde & 1 & 2,0 \\
Limpeza realizada, como, por exemplo, esgoto, água etc. & 1 & 2,0 \\
Forma de evitar doenças & 1 & 2,0 \\
Casa sem banheiro e esgoto a céu aberto & 1 & 2,0 \\
Sei que tem que ser bem tratado para não trazer doenças & 1 & 2,0 \\
Tratamento de água e lixo & 1 & 2,0 \\
Não sei & 22 & 44,0 \\
Nada & 6 & 12,0 \\
Não sei nada & 1 & 2,0 \\
Não & 1 & 2,0 \\
Não sei muito não sobre isso & 1 & 2,0 \\
\hline TOTAL & $\mathbf{5 0}$ & $\mathbf{1 0 0 , 0}$ \\
\hline
\end{tabular}

Fonte: Dados coletados pelo entrevistador, 2018.

Para Vitorino RR et al. (2012) a esquistossomose está ligada a questões de interação do indivíduo com o meio ambiente inclusive nas formas de lazer, como banho em rios e lagos. Entretanto, a população ribeirinha apesar de dizer que toma ou já tomou banho no riacho, como demonstrado, não considera o saneamento básico da população. Para Povisnke LF (2013) a esquistossomose está ligada a questões de interação do indivíduo com o meio ambiente, principalmente com o uso de águas contaminadas com o parasita Schistosoma Mansoni. E o que podemos observar nesta tabela é que $98 \%$ das pessoas entrevistadas utiliza ou já utilizou a água do riacho para tomar banho e lavar roupas, podendo ser uma possível causa de prevalência da esquistossomose nesta população.

Outro ponto proeminente a descobrir foi se existia banheiro nas casas. Das cinquenta moradias, em (43; $86,0 \%)$ têm banheiro e $(7 ; 14,0 \%)$ não tem. Apesar da maioria das casas possuírem banheiro, aquelas moradias, que não tem banheiro tornam-se fatores de risco pra toda população, pois as fezes são depositadas a céu aberto, fazendo com que contamine o Riacho de Canas com o parasita S. mansoni. Na visão de Brasil (2014) a ausência de condições sanitárias permite que fezes contaminadas, depositadas no solo cheguem ao alcance dos moluscos do gênero Biomphalaria, hospedeiros intermediários do Schistosoma mansoni, através da água das chuvas, contaminando coleções hídricas.

No Brasil, a esquistossomose pode-se apresentar em áreas contínuas e contíguas, ao longo do litoral, pois segue as bacias hidrográficas. Logo, percebe-se que essas condições podem causar a migração do parasita, bem como de seu hospedeiro intermediário. Assim, como mostrado no acima é possível notar a deficiência de saneamento familiar e ambiental e também da educação em saúde com a população da localidade. A falta de água potável e de saneamento básico e higiene são responsáveis por 1,9 milhões das taxas de mortalidades por ano e por $4,2 \%$ da carga global de doenças parasitárias (ESPIRITO-SANTO MCC et al., 2015). 
Tabela 4 - Respostas dos entrevistados relacionado a infecção do parasita S. Mansoni, de acordo com o sexo do indivíduo, o número de pessoas que já foram infectados pelo parasita e quantas vezes fizeram tratamento.

\begin{tabular}{|c|c|c|c|c|}
\hline \multicolumn{5}{|c|}{ Infeç̧ão do parasita Schistosoma Mansoni, de acordo com o sexo } \\
\hline \multicolumn{3}{|l|}{ Entrevistados } & Frequência (50) & Percentual (\%) \\
\hline \multirow{2}{*}{\multicolumn{3}{|c|}{$\begin{array}{l}\text { Masculino } \\
\text { Feminino }\end{array}$}} & 18 & 36,0 \\
\hline & & & 32 & 64,0 \\
\hline \multicolumn{5}{|c|}{ Já foram infectados pelo Schistosoma Mansoni } \\
\hline \multirow{3}{*}{ Sim } & Masculino(18) & Feminino (32) & Frequência(50) & Percentual (\%) \\
\hline & & 17 & 26 & 52,0 \\
\hline & & 15 & 24 & 48,0 \\
\hline \multicolumn{3}{|c|}{ Fez tratamento para o Schistosoma Mansoni } & Frequência (50) & Percentual (\%) \\
\hline & 9 & 18,0 \\
\hline \multicolumn{3}{|l|}{ Masculino } & 0 & 0,00 \\
\hline \multirow[t]{2}{*}{ Feminino } & \multirow{2}{*}{\multicolumn{2}{|c|}{$\begin{array}{l}\text { Sim } \\
\text { Não }\end{array}$}} & 16 & 32,0 \\
\hline & & & 1 & 2,0 \\
\hline \multicolumn{3}{|c|}{ Não fizeram tratamento, pois nunca foram infectados } & 24 & 48,0 \\
\hline \multicolumn{3}{|c|}{ Número de vezes que fez tratamento } & Frequência (50) & Percentual (\%) \\
\hline \multirow{2}{*}{\multicolumn{3}{|c|}{ Masculino }} & 7 & 14,0 \\
\hline & & & & \\
\hline \multirow{2}{*}{ Uma vez } & \multicolumn{2}{|c|}{ Feminino } & 7 & 14,0 \\
\hline & \multicolumn{2}{|c|}{ Masculino } & 2 & \\
\hline \multirow[t]{3}{*}{ Duas vezes } & \multirow{2}{*}{\multicolumn{2}{|c|}{ Feminino }} & 8 & 16,0 \\
\hline & & & 0 & 0,0 \\
\hline & \multicolumn{2}{|c|}{ Masculino } & & \\
\hline Mais de quatro vezes & Femini & & 1 & 2,0 \\
\hline \multicolumn{3}{|c|}{ Não fizeram tratamento, pois nunca foram infectados } & 24 & 48,0 \\
\hline
\end{tabular}

Fonte: dados coletados pelo entrevistador, 2018.

A tabela 4 esclarece sobre a Infecção do parasita Schistosoma Mansoni, de acordo com o sexo. Sabendo que $(18 ; 36,0 \%)$ dos entrevistados são do sexo masculino e que $(32 ; 64,0 \%)$ são do sexo feminino, buscouse identificar qual sexo é mais infectado pela doença. Com isso, se questionou se os entrevistados já tiveram o Schistosoma Mansoni, comprovando através da pesquisa que 26 pessoas, sendo nove do sexo masculino e dezessete do sexo feminino, já foram contaminadas pela Schistosoma, o que equivale a $52,0 \%$ da população, comprovando assim que a maioria é composta por infectados do sexo feminino.

Um ponto instigante na pesquisa foi identificar se as pessoas infectadas procuraram tratamento para o Schistosoma Mansoni. Para tanto, se descobriu que vinte e cinco dos vinte e seis infectados, sendo nove do sexo masculino e dezesseis do sexo feminino, afirmaram que procuraram tratamento para a doença, e apenas uma do sexo feminino disse que foi infectada, porém não fez tratamento para o $S$. Mansoni. Vinte e quatro pessoas não fizeram tratamento, pois nunca foram infectados. Na apreciação de Borges LS et al. (2014) todos os pacientes diagnosticados com o Schistosoma Mansoni, devem ser tratados, para evitar a progressão e evolução da doença. 
Outra questão essencial foi descobrir quantas vezes o infectado procurou tratamento. Por certo, se identificou que dos infectados, sete do sexo masculino e sete do sexo feminino logo, $28,0 \%$ da população disseram que já fizeram uma vez o tratamento contra a Schistosoma, dois do sexo masculino $(2 ; 4,0 \%)$ e oito do sexo feminino que equivale a $(8 ; 16,0 \%)$ confirmaram que por duas vezes fizeram tratamento contra a doença. Uma entrevistada do sexo feminino que condiz a $(1 ; 2,0 \%)$ disse que já fez tratamento mais de quatro vezes, também, uma do sexo feminino equivalente a $(1 ; 2,0 \%)$ foi infectada e não fez tratamento e, com grande número alarmante $(24 ; 48,0 \%)$ não fizeram tratamento, pois nunca foram infectados. De acordo com Brasil (2014) indivíduos que moram em áreas endêmicas, é sabido que ocorre a transmissão da doença, e medidas de controle devem ser tomadas para evitar a incidência e prevalência da esquistossômica.

\section{CONCLUSÃO}

Diante do exposto, conclui-se que os fatores de risco para a esquistossomose na população estudada são as condições socioeconômicas precárias, baixo nível de escolaridade, saneamento básico deficiente, ausência de educação sanitária e o Riacho de Canas como possível fonte de infecção. Logo, faz-se necessária medidas urgentes, através da secretaria de meio ambiente, na identificação e controle de moluscos, secretaria de ação social na construção de banheiros, e educação em saúde realizado pela equipe de saúde. É notório a ausência do conhecimento sobre a esquistossomose, como se adquire a doença, sendo que, $50 \%$ dos entrevistados alegam que não sabem como ocorre a infecção pelo Shistosoma Mansoni. E 38\% das pessoas disseram que não conhecem nada sobre a esquistossomose.

\section{REFERÊNCIAS}

1. ABDEL-HAFEEZ EH, et al. Polymerase Chain Reaction: A Better Method for Diagnosing Chronic Schistosoma mansoni infections. Tropical Medicine and Health, v. 43, n. 4, p. 205-209, 2015.

2. BARACHO M. Série Panorama das Doenças negligenciadas: nordestinos morrem mais em decorrência da esquistossomose. Dssbr site. 2013. Disponivel online. Acessado em 09 de dezembro de 2018.

3. BARBOSA CS, et al. Casos autóctones de esquistossomose mansônica em crianças de Recife, PE. Rev. Saúde pública. 2013;47(4):684-90.

4. BORGES LS, et al. Perfil epidemiológico da esquistossomose em comunidade periférica do município de Jequié-BA. Rev. Univ Vale Rio Verde, 2014 ago-dez; 12(2):812-29.

5. BRASIL. Departamento de Vigilância da Esquistossomose Mansoni: diretrizes técnicas $\backslash$ Ministério da Saúde, Secretaria de Vigilância em saúde. Departamento de Vigilância das Doenças Transmissíveis. - 4. Ed.- Brasília: Ministério da Saúde, 2014.

6. BRASIL. Ministério da Saúde (BR). Departamento de Informática do SUS. Programa de Controle da Esquistossomose [internet]. Brasília: Ministério da Saúde; 2014 [citado 2018 mai 4].

7. COLLEY DG. Morbidity control of schistosomiasis by mass drug administration: how can we do it best and what will it take to move on to elimination. Trop Med Health, 2014. Jun;42 Suppl 2:25-32.

8. DUARTE R. Pesquisa qualitativa: reflexões sobre o trabalho de campo. Cad. Pesqui. [online]. 2002, n.115, pp. 139-154. ISSN 19805314.

9. ESPIRITO-SANTO MC, et al. Comparative Study of the accuracy of Different Techniques for the Laboratory Diagnosis of Schistosomiasis Mansoni in Areas of Low Endemicity in Barra Mansa City, Rio de Janeiro State, Brazil. BioMed Research International, v. 15, p. 1-16, 2015.

10. GIL AC. Como elaborar projetos de pesquisa. $5^{a}$ ed. São Paulo: Atlas, 2010

11. GUERRA AJT, CUNHA SB. Geomorfologia e meio ambiente. 11. Ed. Rio de janeiro: Bertrand Brasil, 2012.

12. INIBAYA MT, et al. Prevention and control of schistosomiasis: a current perspective. Rev. Rep Trop Med. 2014 Fev; 2019(5):65-75

13. IBGE, Instituto Brasileiro de geografia e Estatística. Censo Demográfico 2000 - 2015 e pesquisa de orçamento familiar. 2015. Disponível online. Acesso em 23 de março de 2018.

14. JACOBI PR. Aprendizagem social na gestão compartilhada de recursos hídricos: desafios, oportunidades e cooperação entre atores sociais. São Paulo: Annablume, 2013. 162 p.

15. JORDÃO MCC, et al. Caracterização do perfil epidemiológico da esquistossomose no estado de Alagoas. Cad. Graduação. 2014 fev;2(2):175-88

16. POVISNKE LF, PRESTES AFRO. Esquistossomose no vale do Ribeira/SP: incidência e prevenção-levantamento literário. Saúde \& Foco, p. 21-29, 2013

17. SAUCHA CVV, et al. Condições de saneamento básico em áreas hiperendêmicas para esquistossomose no estado de Pernambuco. Epidemial. Serv. Saúde: Brasília, 24(3): 497-506, jul-set, 2015. Disponível online. Acesso em 20 de agosto de 2018.

18. SILVA PCV, DOMINGUES ALC. Aspectos epidemiológicos da esquistossomose hepatoesplênica no Estado de Pernambuco, Brasil. Epidemiol. Serv. Saúde [online]. 2011, vol.20, n.3, pp. 327-336. ISSN 1679-4974. Disponível online. Acesso em 20 de julho de 2018.

19. SUZANNE C, SMELTZER. Tratado de enfermagem médico-cirúrgica. Revisão técnica, Isabel Cristina Fonseca da Cruz, Ivone Evangelista Cabral; tradução Antônio Francisco Dieb Paulo, José Fernando Ferreira de Figueiredo, Patrícia Lydie Vouex - Rio de Janeiro: Guanabara Koogan, 2012.

20. VITORINO RR, et al. Esquistossomose mansônica: diagnóstico, tratamento, epidemiologia, profilaxia e controle. Revista da Sociedade Brasileira de Clínica Médica, v. 10, n. 1, p. 39-45, 2012. 